\title{
Effect of a boomerang-shaped Conchal cartilage graft for Type three Tympanoplasty on Hearing
}

\author{
Snigdha Elaprolu ${ }^{10}$ Arun Alexander $^{10}$ Sivaraman Ganesan $^{1(1)}$ Coimbatore Balakrishnan Manu ${ }^{1(0)}$ \\ ${ }^{1}$ Department of Ear, Nose and Throat, Jawaharlal Institute of \\ Postgraduate Medical Education and Research, Pondicherry, India \\ Address for correspondence Arun Alexander, MBBS, MS (ENT), DNB, \\ Department of ENT, JIPMER, Pondicherry, 605006, India \\ (e-mail: arunalexandercmc@gmail.com).
}

Int Arch Otorhinolaryngol 2020;25(2):e289-e295.

\begin{abstract}
Introduction Chronic suppurative otitis media atticoantral disease (CSOM-AAD) is often associated with ossicular erosion resulting in significant hearing loss. Absence of the stapes suprastructure is a poor prognostic indicator of hearing outcome, which necessitates an effective reconstruction technique for ossicular continuity and restoration of middle ear volume. In the present study, we used a boomerang-shaped conchal cartilage graft.

Objective To evaluate the improvement in hearing using a boomerang-shaped conchal cartilage graft for Type III tympanoplasty in cases of CSOM-AAD in which the stapes suprastructure was absent and to study the incidence of intraoperative/ postoperative complications of this procedure.

Method A total of 21 patients with CSOM-AAD who were found to have absent stapes suprastructure intraoperatively were included. A boomerang-shaped conchal cartilage graft was placed over the stapes footplate for reconstruction following canal wall down mastoidectomy. Pure tone audiogram $(500,1,000,2,000$ and $4,000 \mathrm{~Hz})$ was done preoperatively and at 12 weeks postoperatively. Hearing outcome and incidence of complications were noted.

Results There was a statistically significant reduction in the hearing loss for air conduction and air-bone gap (ABG) of $6.1 \mathrm{~dB}$ and $6.9 \mathrm{~dB}$ respectively $(p<0.05)$. Airbone gap $<30 \mathrm{~dB}$ could be achieved in $71.4 \%$ of the patients as compared with $23.8 \%$

Keywords

- tympanoplasty

- cartilage

- graft

- hearing

- boomerang preoperatively. No significant difference was noted in the bone conduction threshold $(p>0.05)$. A better hearing outcome was observed at higher frequencies $(2,000$, $4,000 \mathrm{~Hz}$ ). No major complications were encountered.

Conclusion A boomerang-shaped conchal cartilage graft is effective when used for Type III tympanoplasty, especially at higher $(2,000,4,000 \mathrm{~Hz})$ frequencies, and is comparable to newer materials such as titanium total ossicular reconstruction prosthesis (TORP). No major intraoperative/postoperative complications were noted.
\end{abstract}

\section{Introduction}

Chronic suppurative otitis media (CSOM) is prevalent in developing countries like India and is more common in lower socioeconomic groups. The overall prevalence rate is 46 and 16 people per thousand in rural and urban populations, respectively. ${ }^{1}$ Chronic suppurative otitis media atticoantral received

July 22, 2019

accepted

April 13, 2020

published online

June 30,2020
DOI https://doi.org/

10.1055/s-0040-1712934.

ISSN 1809-9777.

\footnotetext{
(c) 2020. Fundação Otorrinolaringologia. All rights reserved.

This is an open access article published by Thieme under the terms of the Creative Commons Attribution-NonDerivative-NonCommercial-License, permitting copying and reproduction so long as the original work is given appropriate credit. Contents may not be used for commercial purposes, or adapted, remixed, transformed or built upon. (https://creativecommons.org/ licenses/by-nc-nd/4.0/)

Thieme Revinter Publicações Ltda., Rua do Matoso 170, Rio de Janeiro, RJ, CEP 20270-135, Brazil
} 
(CSOM-AAD) disease is a disease of the middle ear characterized by the presence of cholesteatoma, which is a sac-like structure lined by squamous epithelium with bone eroding properties. Chronic suppurative otitis media is a correctable cause of hearing loss, which can be corrected by a surgical procedure called tympanoplasty. Atticoantral disease almost always requires surgical treatment in the form of canal wall down (CWD) mastoidectomy with Type III tympanoplasty for hearing augmentation. It has been seen in many patients with this disease that there is ossicular erosion necessitating intraoperative removal of the ossicles. The hearing mechanism is repaired by placing a graft over the stapes head when present, allowing the conduction of sound, and it is called Type III tympanoplasty. The techniques used for reconstruction have evolved over the past 50 years and will continue to evolve. These include ossicular repositioning, autograft materials like cortical bone and cartilage, homograft ossicles, synthetic materials like plastipore, hydroxyapatite and bone cement. $^{2,3}$ Recently, materials like glass ionomer cement, titanium and gold prosthesis have been used, which are now widely popular. However, it becomes problematic when the stapes suprastructure is also eroded by disease and a graft placed directly over the stapes footplate results in significant postoperative hearing loss. At present, this problem is corrected by placing a total ossicular prosthesis from the footplate to the graft or a cartilage strut instead of a prosthesis. A prosthesis has a high incidence of extrusion and a short cartilage strut, being mechanically unstable, and does not allow for adequate sound transmission.

To overcome these problems, we propose to use a boomerang-shaped conchal cartilage graft harvested during meatoplasty with one edge touching the stapes footplate and the other end hitched below the bony annulus. This provides a stable assembly, allowing sound transmission and allowing for a pneumatized middle ear even if there is some bare area over the promontory by preventing adhesions.

In the present study, we analyzed the results of reconstruction with a boomerang-shaped conchal cartilage graft over stapes footplate by comparing the pure tone average done preoperatively and at 12 weeks postoperatively. Concurrently, the incidence of complications - wound hematoma/infection (donor site), facial nerve injury, postoperative sensorineural hearing loss and disease recurrence, was noted.

Conchal cartilage has been used worldwide by neurootologic surgeons for $>30$ years. It has been recommended for bridging ossicular chain defects, for tympanic membrane reconstruction and for the repair of bony meatal wall defects. ${ }^{4-8}$ Conchal cartilage is freely available at the surgical site and is available in enough quantity and is of the ideal consistency for all mastoid surgeries. The correction of defects in the ossicular chain involves removing the eroded ossicle, sculpting it and then repositioning it between the remaining ossicles. Various techniques have been described to bridge the defect between the ossicles using biocompatible cement, polycel, glues, etc. Presently, no studies are available for the use of boomerang-shaped cartilage for Type III tympanoplasty in cases where the stapes suprastructure is absent.

\section{Objectives}

Primary objective:

a) To evaluate the improvement in hearing by using a boomerang-shaped conchal cartilage graft for Type III tympanoplasty when the stapes supra-structure is absent.

Secondary objective:

b) To evaluate the incidence of intraoperative/postoperative complications in Type III tympanoplasty with boomerang-shaped conchal cartilage graft

\section{Methodology}

This is a 'before and after intervention study' conducted in the department of ENT from May 2016 to April 2018. All of the patients with atticoantral disease who were planned for tympanomastoid surgery were considered for the present study. Patients who were found to have an absent stapes supra-structure were included in the present study with the exclusion of those with a fixed or an obliterated footplate or a dehiscent facial nerve. Convenient sampling technique was used and a total of 21 patients were recruited according to the above-mentioned criteria.

These 21 patients underwent ossicular reconstruction with the use of boomerang-shaped conchal cartilage graft.

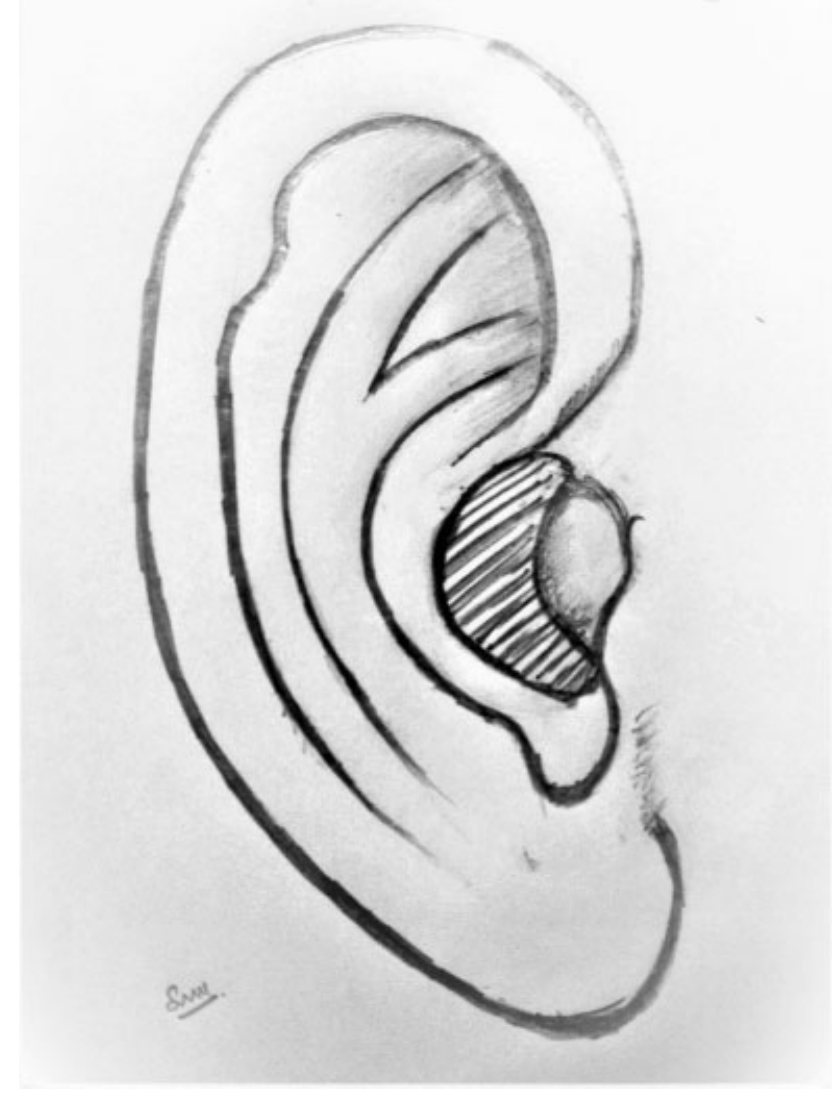

Fig. 1 Site of conchal cartilage graft (shaded area) as part of conchomeatoplasty. 

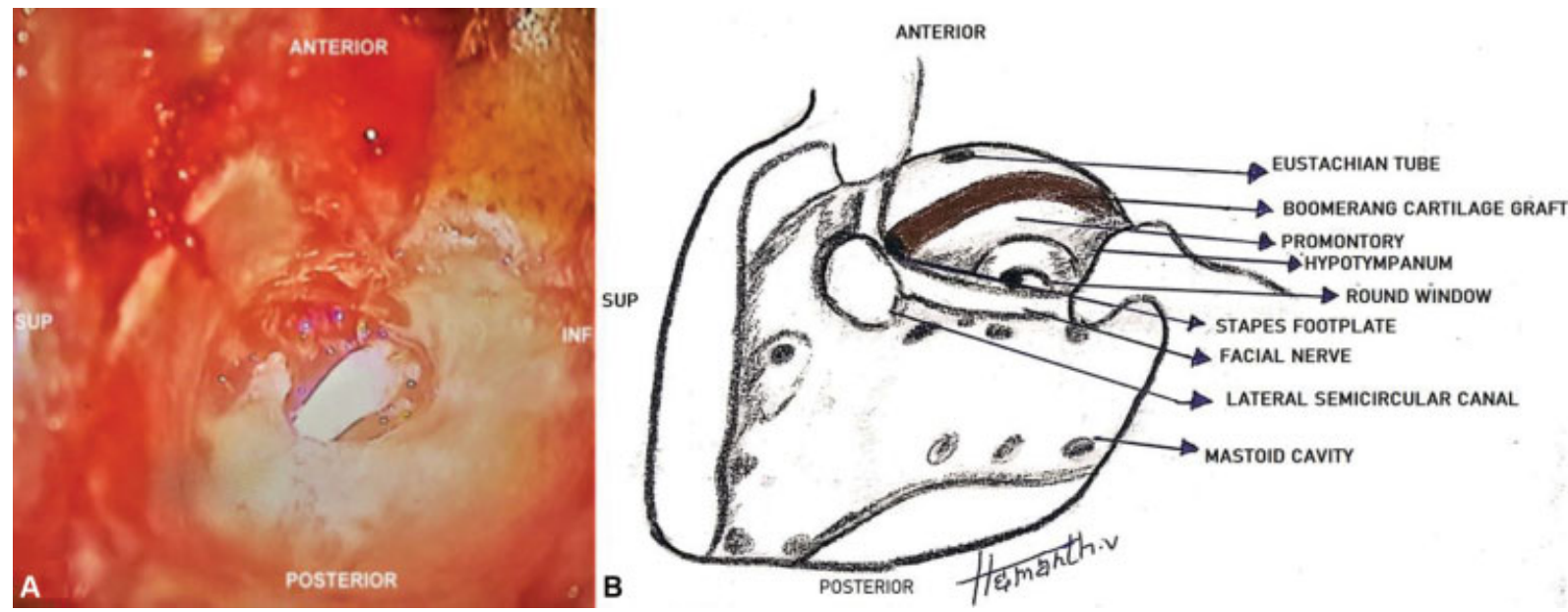

Fig. 2 (A) Intraoperative picture of boomerang shaped conchal cartilage graft placed over the stapes footplate and the other end hitched under the inferior annulus. Dome of the boomerang viewed from lateral aspect. (B) Diagram drawn from - Figure 2.A for better illustration (SUPSuperior, INF- Inferior).

The conchal cartilage was obtained from the conchomeatoplasty ( - Fig. $\mathbf{1}$ ), which is a routine step in CWD mastoidectomy. This conchal cartilage was then sculpted into the shape of a boomerang and placed with one edge touching the stapes footplate and the other end hitched below the inferior bony annulus in the hypotympanum (-Fig. 2). This provides a stable assembly, allowing sound transmission and allowing for a pneumatized middle ear even if there is some bare area over the promontory by preventing the formation of adhesions. A temporalis fascia graft was placed over the cartilage graft and the cavity was lined with the temporalis fascia graft. Antibiotic soaked absorbable Gelatin foam was then placed in the cavity.

The patients were subjected to pure tone audiometry for documenting the hearing loss prior to surgery at the time of the preoperative evaluation in the out patient clinic and then at 12 weeks after surgery at the time of review. Using Pure tone audiometry, air conduction thresholds and bone conduction thresholds were measured at 250, 500, 1000, 2000 and $4000 \mathrm{~Hz}$. The average hearing loss for air conduction and bone conduction at the mentioned frequencies, and the airbone gap (ABG) were calculated and documented.

The independent variables that were studied included age, gender, socioeconomic status and duration of disease. The outcome variable studied included hearing loss in decibels for air conduction and bone conduction at 250, 500, $1,000,2,000$ and $4,000 \mathrm{~Hz}$ obtained from pure tone audiometry both preoperatively and postoperatively. The preoperative average hearing loss for air conduction and bone conduction was compared with the postoperative values recorded at 12 weeks. Descriptive and inferential statistical analyses have been performed in the present study.

Continuous data has been interpreted as mean and standard deviation (SD) (minimum-maximum), and categorical measurements have been presented as percentage (\%). The Student $t$-test (two-tailed, dependent) has been used to find the significance of the study parameters on a continuous scale within one group. The mean and the SD of the hearing loss in decibels preoperatively and postoperatively were compared using the Paired $t$-test. Air and bone conduction thresholds at individual frequencies were compared preoperatively and postoperatively using the paired $t$-test and the Wilcoxon sign test based on the normality of distribution. All of the statistical analyses were performed at 5\% level of significance, and a p-value $<0.05$ was considered significant. The statistical software IBM SPSS Statistics for Windows, Version 19.0 (IBM Corp., Armonk, NY, USA) was used for the analysis of the data.

\section{Results}

The present study was conducted in the department of ear, nose and throat of the Jawaharlal Institute of Postgraduate Medical Education and Research among 21 patients with CSOM-AAD disease who were found to have absent stapes suprastructure while undergoing tympanomastoid surgery. Among these 21 patients, $54.2 \%$ were females. The mean age of the subjects was 30.7 years old, with a SD of 9.5 years, and maximum patients (42.9\%) were found to be between 21 and 30 years years old. The mean duration of symptoms was 3.76 years, with a SD of 2.46

Table 1 Distribution of air conduction thresholds before and after surgery

\begin{tabular}{|l|l|l|}
\hline $\begin{array}{l}\text { Air conduction } \\
\text { thresholds }(\mathrm{dB})\end{array}$ & $\begin{array}{l}\text { Percentage of } \\
\text { patients in the } \\
\text { respective group } \\
\text { preoperatively }\end{array}$ & $\begin{array}{l}\text { Percentage of } \\
\text { patients in the } \\
\text { respective group } \\
\text { postoperatively }\end{array}$ \\
\hline $\mathbf{1 1 - 2 0}$ & 9.5 & 0 \\
\hline $\mathbf{2 1 - 3 0}$ & 4.8 & 23.8 \\
\hline $\mathbf{3 1 - 4 0}$ & 28.6 & 42.9 \\
\hline $\mathbf{4 1 - 5 0}$ & 14.3 & 23.8 \\
\hline $\mathbf{5 1 - 6 0}$ & 28.6 & 9.5 \\
\hline $61-70$ & 14.3 & $0 !$ \\
\hline
\end{tabular}


Table 2 Distribution of air-bone gap before and after surgery

\begin{tabular}{|l|l|l|}
\hline $\begin{array}{l}\text { Preoperative } \\
\text { Air-bone } \\
\text { gap(dB) }\end{array}$ & $\begin{array}{l}\text { Percentage of } \\
\text { patients in the } \\
\text { group } \\
\text { preoperatively }\end{array}$ & $\begin{array}{l}\text { Percentage of } \\
\text { patients in the } \\
\text { group } \\
\text { postoperatively }\end{array}$ \\
\hline $\mathbf{1 1 - 2 0}$ & 9.5 & 38.1 \\
\hline $\mathbf{2 1 - 3 0}$ & 14.3 & 33.3 \\
\hline $\mathbf{3 1 - 4 0}$ & 57.1 & 28.6 \\
\hline $\mathbf{4 1 - 5 0}$ & 19.0 & 0.0 \\
\hline
\end{tabular}

years. Two out of the 21 cases were revision surgeries while the rest underwent surgery for the first time.

Distribution of air conduction thresholds and ABG before and after the surgery are shown in - Tables $\mathbf{1}$ and 2, respectively. The mean preoperative air conduction threshold was found to be $44.4 \mathrm{~dB}$, with a SD of $12.9 \mathrm{~dB}$. The maximum number of patients who had an intact stapes suprastructure had a preoperative $\mathrm{ABG}$ in the 31 to $40 \mathrm{~dB}$ range (57.1\%) (-Table 2).

\section{Hearing Outcome}

\section{Air Conduction Threshold}

The mean preoperative air conduction threshold was obtained at $38.3 \mathrm{~dB} \pm 9.3 \mathrm{~dB}$ as compared with $44.4 \mathrm{db} \pm 12.9$ postoperatively, with a significant improvement of $6.1 \mathrm{~dB}$ (-Table 3). This difference was found to be statistically significant $(p<0.05$, Paired $t$-test).

\section{Air-bone Gap}

The mean preoperative $A B G$ was $33 \mathrm{~dB}$ and the mean postoperative $A B G$ obtained was $26.1 \mathrm{~dB}$ in the present study. There was a significant improvement of $6.9 \mathrm{~dB} A B G$ postoperatively as compared with the preoperative $A B G(p<0.05$, Paired $t$-test) (-Table 3 ).

\section{Bone Conduction Threshold}

In contrast to the air conduction threshold, there was no significant difference between preoperative and postoperative bone conduction thresholds $(p>0.05)$ which was analyzed by the Wilcoxon sign test.

\section{Frequency-Specific Hearing Outcomes}

Significant hearing improvement was noted at high frequencies thresholds $(2,000$ and $4,000 \mathrm{~Hz})$ with this technique, compared with insignificant improvement at low frequencies. The frequency-specific hearing results obtained by this technique showed significant improvement especially at $4,000 \mathrm{~Hz}$. Both pure tone average and the ABG at $4,000 \mathrm{~Hz}$ showed statistically significant improvement after surgery $(p<0.05)$ (-Table 4).

\section{Complications}

None of the patients had any significant intraoperative complications.

Two patients (9.5\%) had postoperative cavity infection that resolved with a course of antibiotics. There was no incidence of postoperative facial nerve palsy or sensorineural hearing loss/dead ear.

The mean follow-up period of the patients included in the present study was 11.7 months (3-24 months). None of the patients had disease recurrence during the follow-up period.

\section{Discussion}

Chronic suppurative otitis media atticoantral disease is known for cholesteatoma formation leading to ossicular erosion and various other complications. The standard of care for atticoantral disease is surgery. Ossiculoplasty is required in between 40 and $90 \%$ of all tympanoplasties. ${ }^{9}$ The present study included 21 patients who had CSOM$\mathrm{AAD}$ and were found to have absent stapes supra-structure during tympanomastoid surgery, and a boomerang-shaped conchal cartilage graft was used for ossicular reconstruction.

Why the boomerang shape? A boomerang is a thrown tool that traditionally has two arms at an angle. In the present study, when a boomerang-shaped conchal cartilage graft was used, it not only enabled sound conduction by maintaining contact between the neo-tympanum and the stapes footplate, but the apex of the boomerang is believed to act as a fulcrum providing leverage which is then transmitted to the stapes footplate.

Second is the stability of the graft. While one arm of the boomerang rests on the stapes footplate, the other arm lies in the hypotympanum hitched under the inferior bony annulus. This gives anchoring stability to the graft and prevents unwanted displacement of the graft/lateralisation of the graft that is a common disadvantage encountered while using a cartilage strut or a titanium Total Ossicular Replacement Prosthesis (TORP).

Third, the loss of ossicles with the exemption of a mobile stapes footplate often results in a conductive hearing loss of $60 \mathrm{~dB}$. As compared with a normal middle ear, if a Type IV tympanoplasty were to be done, it would result in a shallow middle ear with a significant reduction in middle ear volume as well as a loss of ossicular coupling (-Fig. 3). A boomerang-

Table 3 Comparison of the preoperative and postoperative hearing levels

\begin{tabular}{|l|l|l|l|l|l|}
\hline Hearing thresholds & Preoperative mean $\pm S D$ & Postoperative mean $\pm S D$ & Difference & T value & $p$-value \\
\hline Air conduction & $44.4 \mathrm{~dB} \pm 12.9 \mathrm{~dB}$ & $38.3 \pm 9.3 \mathrm{~dB}$ & $6.1 \mathrm{~dB}$ & 2.12 & $0.048^{*}$ \\
\hline Air-bone Gap & $33 \mathrm{~dB} \pm 8.5 \mathrm{~dB}$ & $26.1 \pm 7.3 \mathrm{~dB}$ & $6.9 \mathrm{~dB}$ & 2.87 & $0.027^{*}$ \\
\hline
\end{tabular}

Abbreviation: SD, standard deviation.

*Paired t-test. 
Table 4 Comparison of the hearing outcomes at low frequencies and at high frequencies

\begin{tabular}{|l|l|l|l|l|l|}
\hline Parameter compared & $\begin{array}{l}\text { Preoperative } \\
\text { mean(dB) }\end{array}$ & $\begin{array}{l}\text { Postoperative } \\
\text { mean (dB) }\end{array}$ & Mean difference(dB) & T value & $p$-value \\
\hline $\begin{array}{l}\text { Air Conduction thresholds at low } \\
\text { frequencies }(250,500,1000 ~ H z)\end{array}$ & 43.65 & 39.37 & 4.2 & 1.47 & 0.157 \\
\hline $\begin{array}{l}\text { AC thresholds at high frequencies } \\
(2,000,4,000 \mathrm{~Hz})\end{array}$ & 45.60 & 38.10 & 7.5 & 2.201 & $0.040^{*}$ \\
\hline
\end{tabular}

${ }^{*}$ Paired t-test.

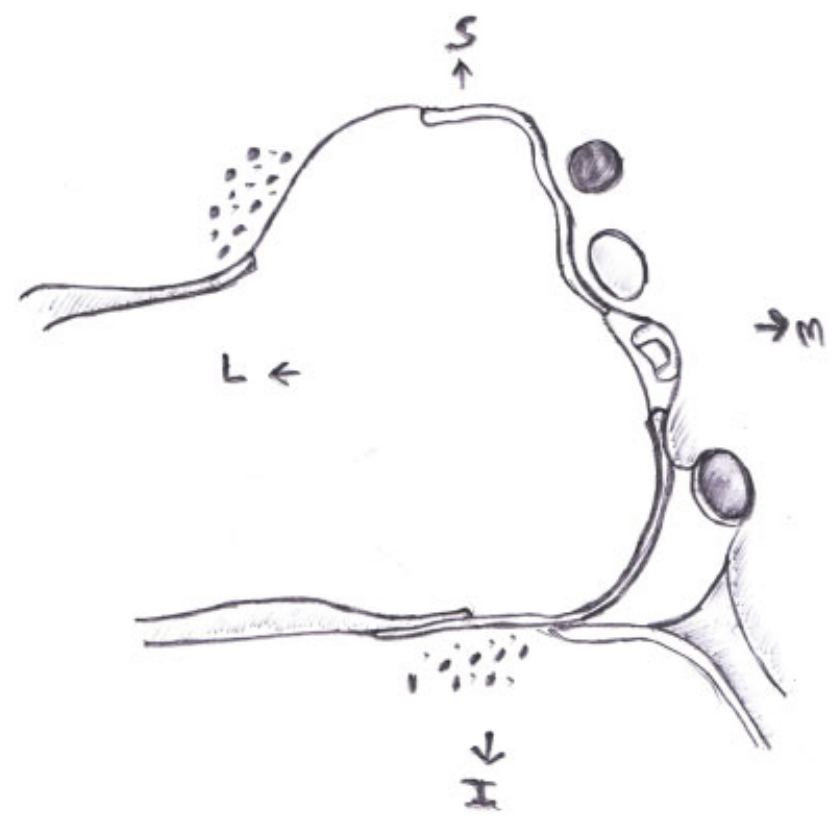

Fig. 3 Ossicular erosion leaving only the mobile stapes footplate in place. Showing a shallow middle ear cavity if type IV tympanoplasty were to be done.

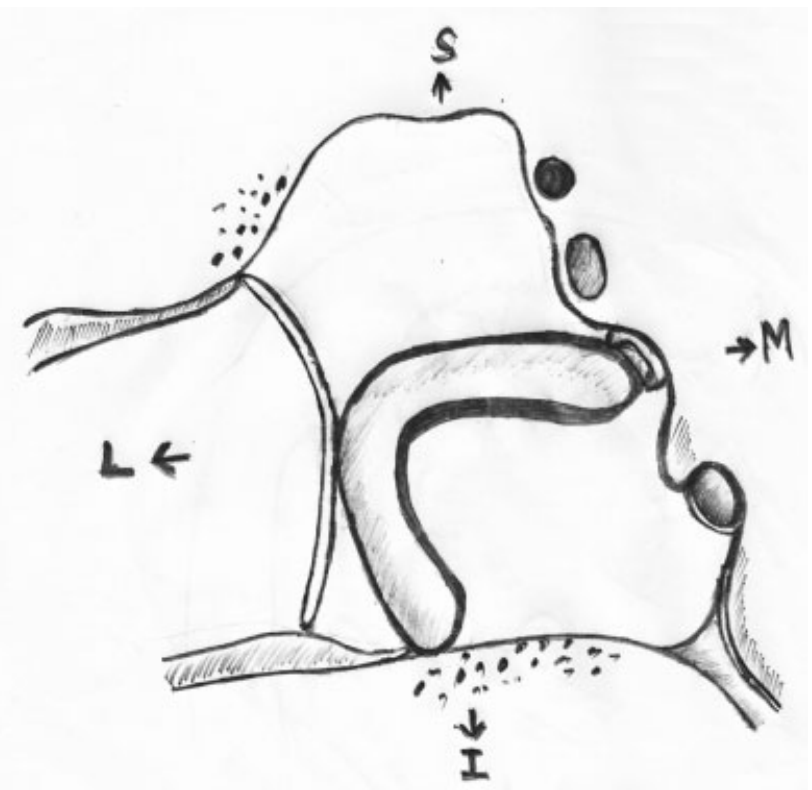

Fig. 4 Boomerang-shaped conchal cartilage graft placed over the footplate while the other end is hitched under the inferior annulus with significant gain in middle ear volume. shaped graft maintains the middle ear volume for aeration with a bowing architecture from the footplate to the hypotympanum (-Fig. 4), which is believed to better withstand the poor negative pressures in the middle ear as compared with synthetic materials or struts. It also prevents the formation of adhesions between the neotympanum graft and the promontory.

Using this technique, the mean preoperative $A B G$ was found to be $33 \mathrm{~dB} \pm 8.54 \mathrm{~dB}$. We have obtained a mean postoperative $A B G$ of $26.1 \mathrm{~dB} \pm 7.31 \mathrm{~dB}$. There was a significant improvement of $6.9 \mathrm{~dB}$ in $\mathrm{ABG}$ postoperatively $(p<0.05)$. No significant changes in preoperative and postoperative bone conduction threshold were noted $(p>0.05)$.

Our patients had absent stapes supra-structure, which can theoretically result in a hearing loss of up to $60 \mathrm{~dB}$ due to loss of ossicular coupling. The present study has an innate fallacy in that it inevitably includes a certain number of cholesteatoma hearers, that is, patients who have a cholesteatoma sac bridging the ossicular defects and hence have a good preoperative hearing. In such cases, the eradication of the disease per se leads to a loss of this pathologic sound transforming mechanism which worsens hearing, based on the extent of the disease. Even though the result of $6.9 \mathrm{~dB}$ is statistically significant, its clinical significance should be interpreted considering this fallacy.

All of our patients underwent canal wall down mastoidectomy due to advanced disease or unreliable follow-up. Şevik Eliçora et al stated that CWD mastoidectomy is done primarily to obtain a dry and safe ear, hence even if the hearing is the same it may be regarded as successful. ${ }^{10}$ However, in the present study, hearing reconstruction is done with a boomerang-shaped conchal cartilage over a mobile stapes footplate.

Shinnabe et al stated that aeration around the stapes had a positive correlation with postoperative hearing results. ${ }^{11}$ CWD mastoidectomies typically result in middle ear air spaces being reduced to that contained behind the tympanic membrane graft, which has a small effect on middle ear sound transmission, which is further worsened by poor eustachian tube function. A boomerang-shaped conchal cartilage, in addition to providing ossicular coupling, also improves middle ear aeration by increasing the middle ear volume especially around the stapes footplate.

Gupta et al conducted a study to compare the hearing outcomes in various tympanoplasties using autologous incus grafts and achieved an $\mathrm{ABG}$ of $<30 \mathrm{~dB}$ in $70 \%$ of the patients who underwent Type III tympanoplasty. ${ }^{12}$ Desaulty et al conducted a study using autografts (incus and cortical 
Table 5 Comparison of the final hearing outcome of the current study with similar studies

\begin{tabular}{|l|l|l|}
\hline Study & The material used for reconstruction & $\begin{array}{l}\text { Postoperative air-bone gap } \leq 30 \text { dB obtained in } \\
\text { cases with }<30 \text { dB Postoperative air-bone gap }\end{array}$ \\
\hline Current study & Boomerang-shaped conchal cartilage graft & $\mathbf{7 1 . 4 \%}$ \\
\hline Gostian et al & Titanium prosthesis with cartilage shoe & $76 \%$ \\
\hline House et al $^{16}$ & Titanium/plastipore & $77.8 \%$ \\
\hline Gupta et al & Autologous bone & $70 \%$ \\
\hline Desaulty et al & Autologous bone & $78 \%$ \\
\hline Gardner et al & Titanium TORP & $70 \%$ \\
\hline
\end{tabular}

Abbreviation: TORP, total ossicular replacement prosthesis.

bone) in Type III tympanoplasty when stapes supra-structure was absent and achieved an $A B G \leq 30 \mathrm{~dB}$ in $78 \%$ of the patients. $^{13}$ The results of these studies which have used autografts are comparable to the results of our study.

In a study conducted by Şevik Eliçora et al, 50 patients underwent Type III tympanoplasty over stapes footplate using either hydroxyapatite TORPs, autologous cortical bone or ossicles. Of these, the best results were obtained when the incus was used for reconstruction with a significant improvement of $8.09 \mathrm{~dB}$ in the $\mathrm{ABG}$ resulting in a postoperative $A B G$ of $27.6 \mathrm{~dB},{ }^{10}$ stating the sustainability of autografts in the evolution of ossicular reconstruction. This is also supported by a study conducted by Malhotra et al which showed that the hearing outcomes obtained with autologous TORPs (cartilage and cortical bone) were as successful as those obtained using titanium prostheses.

Gostian et al studied 42 ears that underwent Type III tympanoplasty using titanium TORP. They studied that the displacement of the prosthesis is a major cause of conductive hearing loss, resulting in up to 50 to $60 \mathrm{~dB}$, known as 'transmission block'. To overcome prosthesis displacement, Gostian et al used a cartilage shoe over the oval window to anchor the TORP. They achieved a postoperative ABG $<30 \mathrm{~dB}$ in $76 \%$ as compared with $64 \%$ preoperatively. They also noted that the hearing gain was poorer in canal wall down procedures as compared with intact canal wall procedures. After CWD surgery $(n=18)$, the PTA-ABG was reduced from a mean (SD) of $33.0 \mathrm{~dB}$ to $24.6 \mathrm{~dB}^{14}$ In our study, the stable assembly made by the boomerang shape and its one end hitching below the inferior annulus is believed to overcome the aforementioned 'transmission block'.

Iñiguez-Cuadra et al stated that 'successful hearing' that is, an $A B G<20 \mathrm{~dB}$, may be obtained in 20 to $55 \%$ of those patients in whom the stapes supra-structure is missing. They conducted a study using titanium TORP in 85 patients. The ABG improved from a preoperative mean of $23.84 \mathrm{~dB}$ to a postoperative mean of $15.41 \mathrm{~dB}$ (mean improvement of $8.43 \mathrm{~dB}) .{ }^{15}$ However, this includes both Canal wall up (CWU) and CWD procedures. - Table 5 shows the final hearing outcomes as a result of the present study in comparison to other Type III tympanoplasties using various reconstruction materials.

Iñiguez-Cuadra et al, on using titanium TORPs, achieved better sound transmission at higher frequencies $(2,000,4,000 \mathrm{~Hz})$ than at low frequencies $(500 \mathrm{~Hz}, 1,000 \mathrm{~Hz}){ }^{15}$
Choi et al noted that air conduction threshold and ABGs had significant improvement mainly at lower and mid-range frequencies following surgery for chronic otitis media, and that the majority showed unfavorable results at high frequencies and recommended hearing rehabilitation at high frequencies. ${ }^{18}$ In contrast to their study, our technique shows significant improvement at high frequencies and is comparable to the study conducted by Iñiguez-Cuadra et al, who used titanium prosthesis. This suggests that boomerang-shaped conchal cartilage graft for Type III tympanoplasty when the stapes suprastructure is absent is indeed an effective technique for ossicular reconstruction, and the hearing outcomes are comparable with those of other studies using newer materials like titanium and hydroxyapatite, which are used for the same purpose. This technique particularly favored better hearing outcomes at $4,000 \mathrm{~Hz}$. Thus, even in this modern era with the continuous evolution of materials that can be used in tympanoplasty, conchal cartilage graft remains a good alternative for Type III tympanoplasty when the stapes supra-structure is absent.

The advantages of this technique are that conchal cartilage, being an autograft, is a safe material, readily available at the site of surgery, from conchomeatoplasty, which is routinely done as part of the surgery following canal wall down mastoidectomy. There is no risk of extrusion/migration. It is free of cost unlike other artificial biomaterials such as titanium prosthesis which are expensive, thus limiting its use in patients of low socioeconomic status especially when CSOM has been found to be closely linked to poor socioeconomic status.

Disadvantages of autografts like bone and cartilage include the chance of resorption over a long time and extended duration of surgery for sculpting the grafts. ${ }^{15}$ However, studies have shown that for chronic ear disease with poor eustachian tube function and revision surgeries, autologous materials are more advantageous as compared with synthetic prostheses. ${ }^{5}$

The limitations of the present study are that the postoperative hearing was assessed only at 12 weeks, and a longer follow-up is necessary as we are largely unaware of the plight of hearing as far as long-term benefits are concerned. There have been many other studies which are of the opinion that short-term results are a more accurate reflection of tympanoplasty, as the long-term results are dependent on several factors such as eustachian tube function, middle ear mucosal condition and stability, fibrosis, adhesions, tympanosclerosis, etc. ${ }^{12,19}$ Our study also had a limited sample size of 21 
due to the short duration of the study. As a result, we were also unable to compare the hearing outcomes of boomerang shaped conchal cartilage graft with other methods of reconstruction such as cartilage struts and titanium TORP.

\section{Conclusion}

The present before and after intervention study conducted among patients with CSOM-AAS with an absent stapes supra-structure has shown that boomerang-shaped conchal cartilage graft effectively improves hearing when used for Type III tympanoplasty over the stapes footplate. No significant intraoperative or postoperative complications were noted with the boomerang-shaped conchal cartilage graft. A significant improvement in air conduction threshold and ABG was noted at $4,000 \mathrm{~Hz}$ as compared with other frequencies using this technique.

\section{Conflict of Interests}

The authors have no conflict of interests to declare.

\section{References}

1 Lalwani AK. Current Diagnosis \& Treatment in Otolaryngology: Head \& Neck Surgery. Lange Medical Books/McGraw Hill; 2004: 1084

2 Kartush JM, Balough BJ. Contemporary ossiculoplastic options. Curr Opin Otolaryngol Head Neck Surg 2001;9(05):272

3 Hillman TA, Shelton C. Ossicular chain reconstruction: titanium versus plastipore. Laryngoscope 2003;113(10):1731-1735

4 Puls T. Tympanoplasty using conchal cartilage graft. Acta Otorhinolaryngol Belg 2003;57(03):187-191

5 Brockman SJ. Cartilage graft tympanoplasty type 3. Laryngoscope 1965;75(09):1452-1461

6 Jansen C. CARTILAGE-TYMPANOPLASTY. Laryngoscope 1963; 73:1288-1301

7 Salen B. MYRINGOPLASTY USING SEPTUM CARTILAGE. Acta Otolaryngol Suppl 1964;188(Suppl 188):188, 82
8 Adkins WY, Osguthorpe JD. Use of a composite autograft to prevent recurrent cholesteatoma caused by canal wall defects. Otolaryngol Head Neck Surg 1984;92(03):319-321

9 Manual ofÂ Middle Ear Surgery, Volume 2 [Internet]. [cited 2018 Jun 15]. Available from: https://www.thieme.com/books-main/ otolaryngology/product/2580-manual-of-middle-ear-surgeryvolume-2

10 Şevik Eliçora S, Erdem D, Dinç AE, Damar M, Bişkin S. The effects of surgery type and different ossiculoplasty materials on the hearing results in cholesteatoma surgery. Eur Arch Otorhinolaryngol 2017;274(02):773-780

11 Shinnabe A, Hara M, Hasegawa M, et al. Relationship between postoperative aeration around the stapes and postoperative hearing outcome after canal wall down tympanoplasty with canal reconstruction for cholesteatoma. Otol Neurotol 2011;32(08): $1230-1233$

12 Gupta S, Kalsotra P. Hearing gain in different types of tympanoplasties. Indian J Otol. 2013;19(04):186

13 Desaulty A, Shahsavari S, Pasquesoone X. [Ossicular reconstruction with autograft in type III]. Rev Laryngol Otol Rhinol (Bord) 2005;126(01):19-23

14 Gostian A-O, Kouamé J-M, Bremke M, Ortmann M, Hüttenbrink K$B$, Beutner D. Long-term Results of the Cartilage Shoe Technique to Anchor a Titanium Total Ossicular Replacement Prosthesis on the Stapes Footplate After Type III Tympanoplasty. JAMA Otolaryngol Head Neck Surg 2016;142(11):1094-1099

15 Iñiguez-Cuadra R, Alobid I, Borés-Domenech A, Menéndez-Colino L-M, Caballero-Borrego M, Bernal-Sprekelsen M. Type III tympanoplasty with titanium total ossicular replacement prosthesis: anatomic and functional results. Otol Neurotol 2010;31(03): 409-414

16 House JW, Teufert KB. Extrusion rates and hearing results in ossicular reconstruction. Otolaryngol Head Neck Surg 2001;125 (03):135-141

17 Gardner EK, Jackson CG, Kaylie DM. Results with titanium ossicular reconstruction prostheses. Laryngoscope 2004;114(01):65-70

18 Choi H-G, Lee DH, Chang KH, Yeo SW, Yoon SH, Jun BC. Frequencyspecific hearing results after surgery for chronic ear diseases. Clin Exp Otorhinolaryngol 2011;4(03):126-130

19 Kolo ES, Ramalingam R. Hearing Results Post Tympanoplasty: Our Experience with Adults at the KKR ENT Hospital, India. Indian J Otolaryngol Head Neck Surg 2014;66(04):365-368 